\title{
Electronically Controlled Expansion Valve for Use in a Geothermal Heat Pump System
}

\author{
H. I. Abu-Mulaweh ${ }^{a} *$, D. W. Mueller ${ }^{a}$, H. Oloomi ${ }^{b}$ \\ ${ }^{a}$ Department of Mechanical Engineering, Purdue University at Fort Wayne, IN, 46805, USA \\ ${ }^{b}$ Department of Electrical Engineering, Purdue University at Fort Wayne, IN, 46805, USA
}

\begin{abstract}
This paper presents a detailed design of a development control board that can control an electronic expansion valve in a geothermal heat pump. The design utilized a microcontroller based system with a fuzzy control algorithm, and a temperature and pressure sensor configuration at the inlet of the compressor. The fuzzy control was designed and simulated using Simulink in Matlab. The control algorithm takes the information that the microcontroller obtained from the pressure and temperature sensor and adjusts the valve accordingly to control the amount of superheat. The controller was able to bring the superheat to the desired set point of $10^{\circ} \mathrm{F} \pm 2^{\circ} \mathrm{F}$ and maintain it.
\end{abstract}

Keywords: Expansion valve, Geothermal, Electronic control, Heat pump

\section{Introduction}

A traditional geothermal heat pump consists of five basic components: compressor, condenser, evaporator, reversing valve, and expansion device. In a geothermal system, the earth loop is located below the frost line to take advantage of the earth's constant temperature. A coolant line from the earth loop is connected to the coax heat exchanger in the heat pump system. The coax heat exchanger acts as an evaporator in the heating mode (Fig. 1a), and a condenser in the cooling mode (Fig. 1b).

The expansion devices come in different forms, such as capillary tubes which are used in refrigerators and window air conditioners, thermal expansion valves which are used in many geothermal heat pumps, and electronic expansion valves which allow for use with variable speed compressors. Capillary tube is simple and not expensive. However, its flow regulation is limited to a very small range of flow conditions. Thermostatic expansion valves are more advanced and they use a proportional feedback action control mechanism to keep evaporator superheat at constant value. However, they are not appropriate for a wide range of flow conditions because its control system is simple (see for example; Broersen and Van Der Jagt [1], and Mithraratnel and Wijeysundera [2], and Chen, et al. [3]). It is controlled by springs, bellows, and push rods. On the other hand, the electronic expansion valve has a much more sophisticated design. Electronic expansion valves provide higher system efficiency, can be used on different tonnage systems and can be controlled more precisely than other types of expansion valves (see for example; Outtagart, et al. [4], Aprea and Mastrullo [5], Lazzarin, et al. [6], and Lazzarin and Noro [7]. In order to use an electronic expansion valve in a system, a controller that integrates into the thermal system must be used.

There are two types of electronic expansion valves: the superheat control expansion valve and the intermediate pressure control expansion valve. These electronic expansion valves expand the liquid refrigerant and converts it into a lowtemperature, low-pressure atomized refrigerant. At the same time, they regulate the amount of refrigerant to be supplied to the interior evaporator or to the exterior heat exchanger.

WaterFurnace International in Fort Wayne, Indiana, has the need for a control board that can control an electronic expansion valve (EEV) in a reversible heat pump (heating and cooling modes). The board must be able to control superheat in the refrigeration circuit of a geothermal heating/cooling

${ }^{*}$ Corresponding author. Tel.: +260-481-6357

Fax: +260-481-6281; E-mail: mulaweh@engr.ipfw.edu

(C) 2014 International Association for Sharing Knowledge and Sustainability

DOI: $10.5383 /$ ijtee.07.01.001 
system to a specific set point of $10^{\circ} \mathrm{F}+/-2^{\circ} \mathrm{F}$ of superheat at the inlet of the compressor. The board will be designed to control a $12 \mathrm{~V}$ DC stepper motor that will be used to open and close an electronic expansion valve.

This paper presents a detailed design of the control board that was requested by the sponsor of this project. Four different system tests are presented to validate the proposed design.

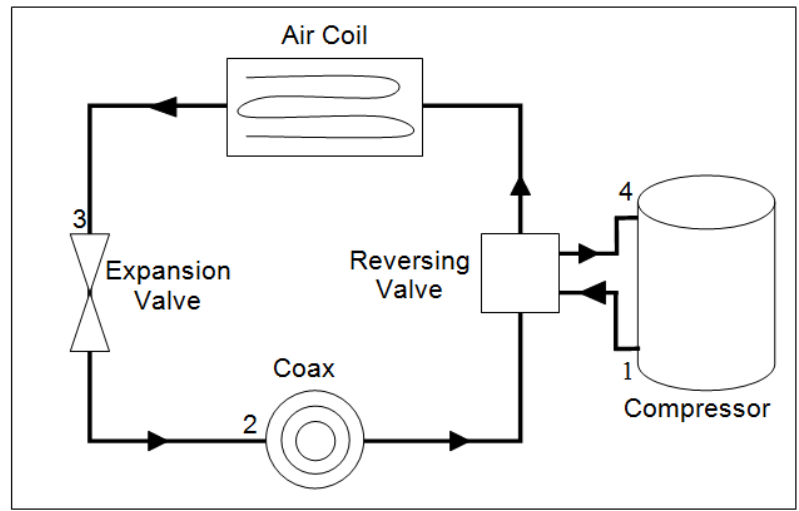

(a)

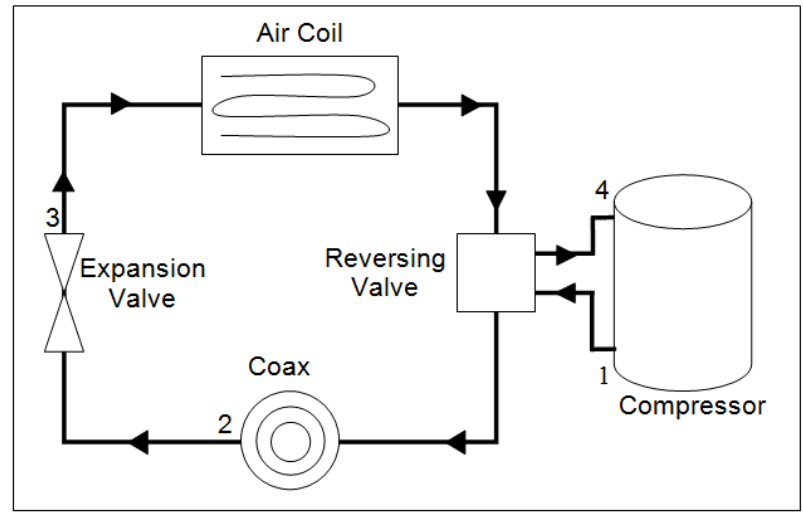

(b)

Fig. 1 Schematics of the geothermal heat pump compression vapor cycle (a) heating mode, (b) cooling mode

\section{The Design Process and Specifications}

The design process that was employed is the one outlined by Bejan et al. [8] and Jaluria [9]. The first essential and basic feature of this process is the formulation of the problem statement. The formulation of the design problem statement involves determining the requirements of the system, the given parameters, the design variables, any limitations or constraints, and any additional considerations arising from safety, financial, environmental, or other concerns. The following is a summary of the guidelines:

- Refrigerant $-410 \mathrm{~A}$ refrigerant will be used in this system and must be controlled within/throughout the following components:

- Superheated vapor must exit the compressor

- The inlet of the compressor must have $10^{\circ} \mathrm{F}$ of superheat $+/-2^{\circ} \mathrm{F}$

- A refrigerant temperature of $15^{\circ} \mathrm{F}$ to $250^{\circ} \mathrm{F}$ throughout the entire system
- As the superheat in the system rises above the set point of $10^{\circ} \mathrm{F}+/-2^{\circ} \mathrm{F}$ the control will need to open the expansion valve to bring the superheat value down.

- As the superheat in the system falls below the set point the control board will need to close the valve to raise the superheat back to the acceptable level.

- Control Operating Voltage

- The board must operate with a supply voltage of 18 to 30 Volts $\mathrm{AC}$ at $50 / 60 \mathrm{~Hz}$.

- The board must have low voltage protection that will suspend operation of the board if the supply voltage falls below 18 Volts AC.

- Temperature or Pressure Transducers - Two or more sensors, either temperature or pressure, must be interfaced with the control board. All temperature sensors that the board uses must be a $10 \mathrm{~K} \Omega$ negative temperature coefficient type.

- Pressure sensors are used to calculate saturation temperature, $\mathrm{T}_{\mathrm{sat}}$. The operating range for the temperature sensor is 0 to 1000 psi.

- Temperature sensors are used to calculate superheat temperature, $T^{*}$, from the $T_{\text {sat }}$ measurement.

- Software - Must be able to control stepper motor of the EEV to regulate the mass flow rate of refrigerant.

After the problem statement was formulated, several conceptual designs were considered and evaluated. Each design concept was evaluated by the following criteria: Effectiveness, Cost, Safety, and Size. The final design that was developed and constructed consisted of a microcontroller based board loaded with a fuzzy control algorithm, and interfaced with one pressure sensor and one temperature sensor. The fuzzy control algorithm takes the information that the microcontroller obtained from the pressure and temperature sensor and then adjusts the valve accordingly to control the amount of superheat.

\section{Fuzzy control}

A fuzzy control is a control that is designed around a set of ifthen rules. The fuzzy controller is also made up of an inference mechanism, a fuzzification inference, and a defuzzification inference. Figure 2 illustrates a simplified block diagram of a proportional derivative (PD) fuzzy controller. In Figure 2 the following variables are used to create the base rules:

e: error, which is the superheat temperature going into the compressor.

$\frac{d T}{d t}$ : change in error. Change in superheat with respect to the change in time.

$\mathrm{G}_{1}$ : Integral of the superheat.

h: Gain for the system.

u: Amount of steps the EEV needs adjusted.

Each of these three variables (e and $\frac{d T}{d t}$ as inputs and $u$ as the output) will need to have ranges assigned to them so that rules can be wrote for the system. The fuzzy control can be designed and simulated using Simulink in Matlab. 


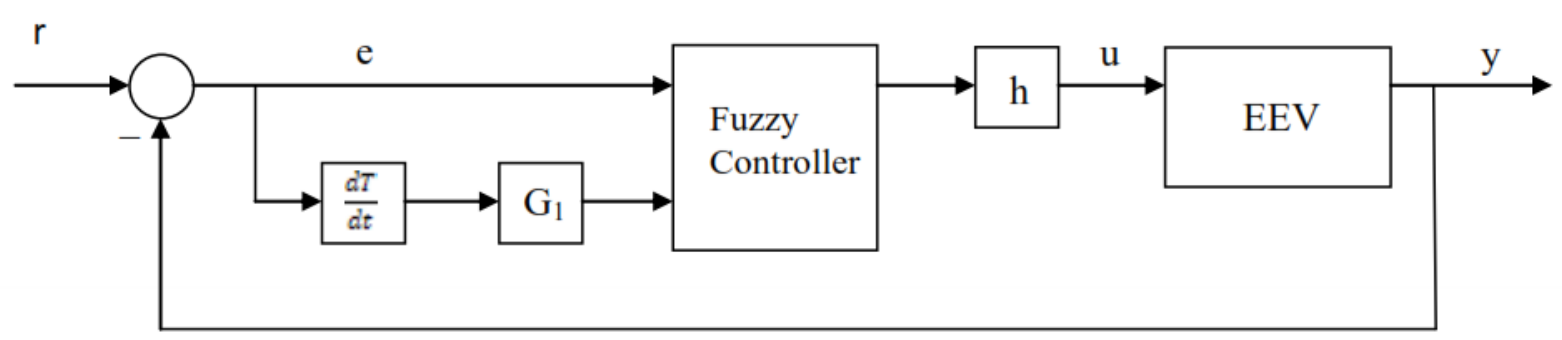

Fig. 2: Block diagram of fuzzy controller

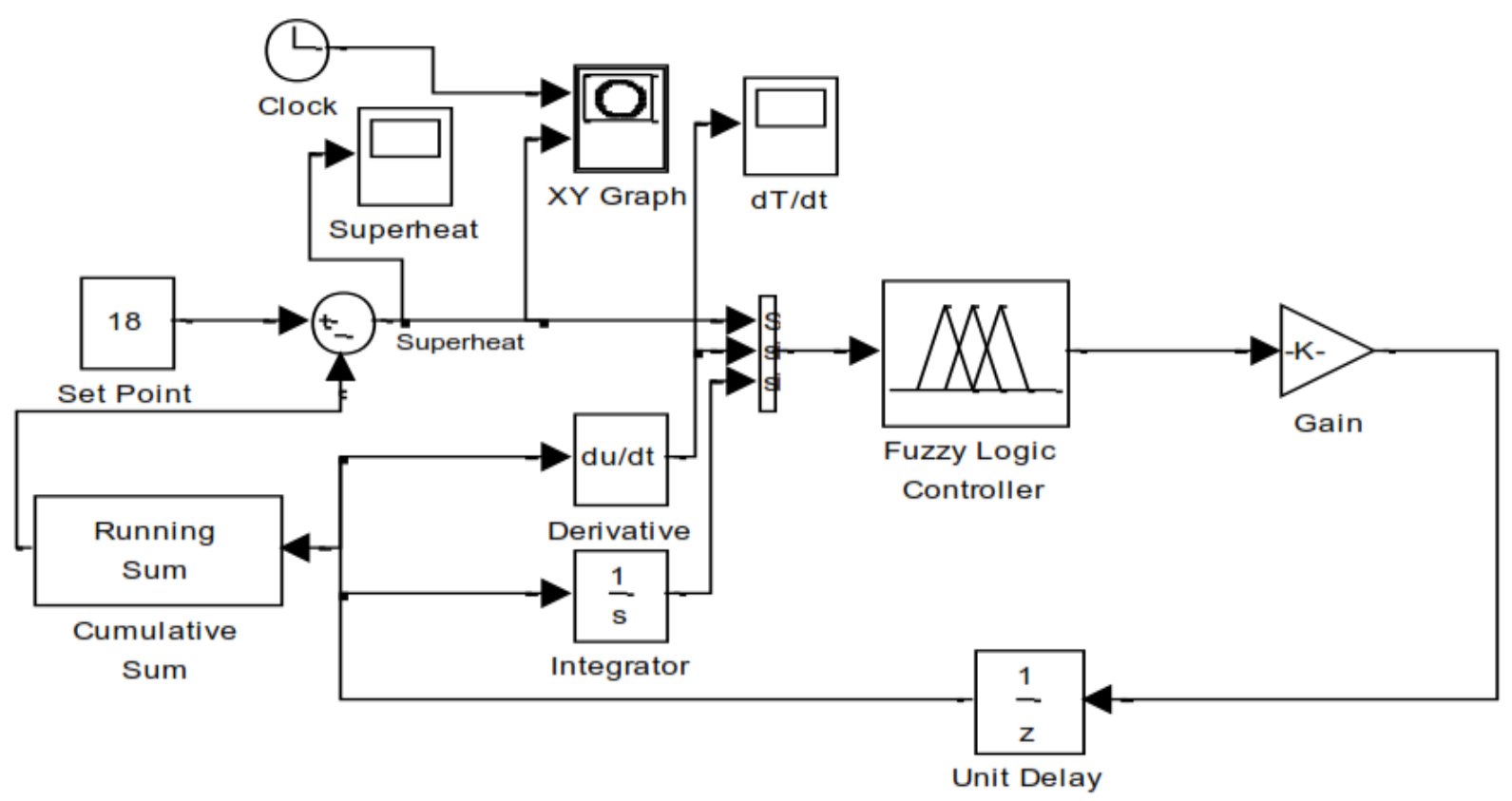

Fig. 3: Simulink model

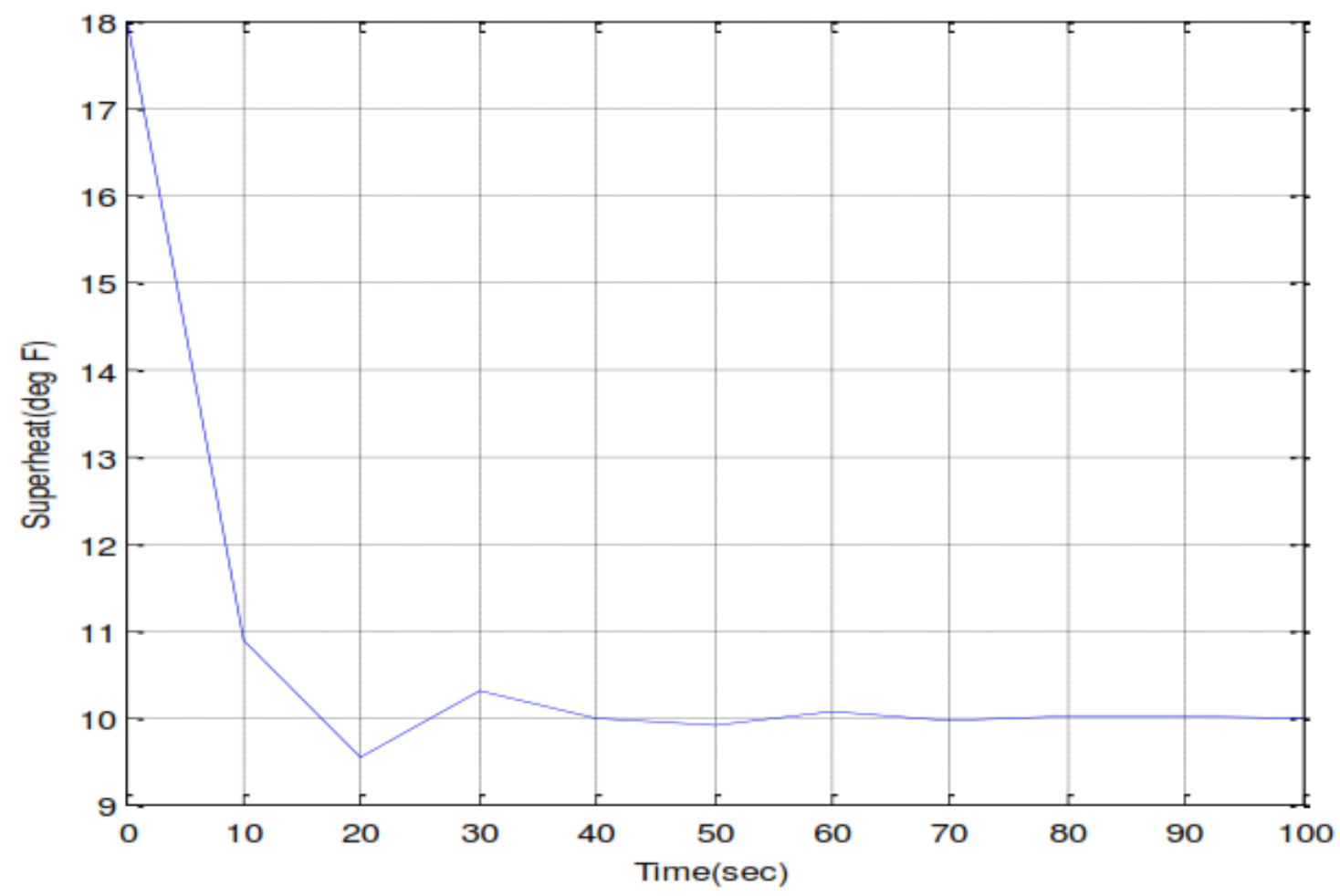

Fig. 4: Superheat as controlled by the fuzzy control 


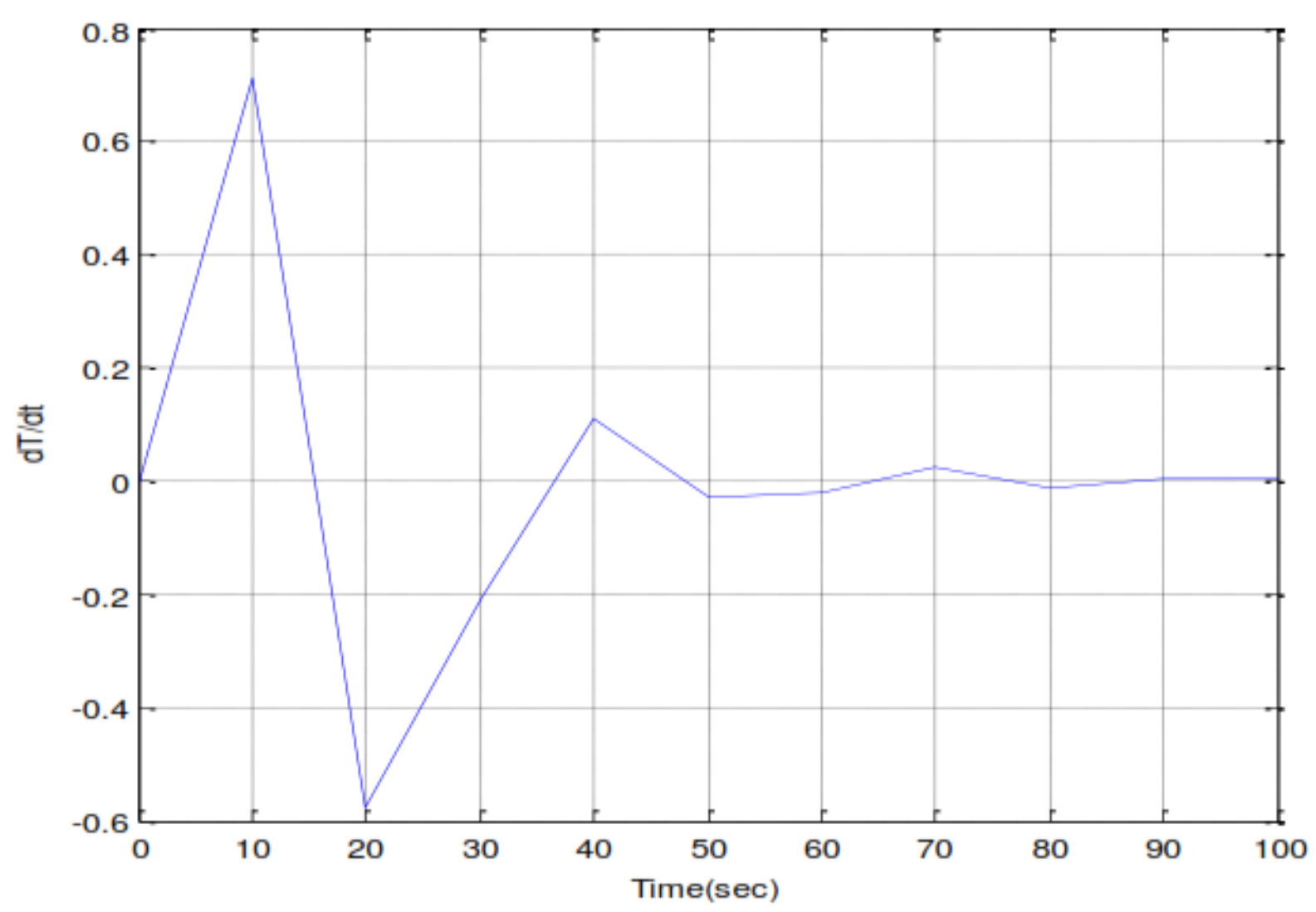

Fig. 5: Derivative of superheat

\section{Simulink}

MatLab's Simulink is used for simulation purposes of the EEV fuzzy control. Figure 3 is a diagram of the model used to simulate how the fuzzy control will be able to adjust the EEV to reach the target superheat of $10^{\circ} \mathrm{F}$.

Each of the elements in the diagram performs different tasks. The set point block is the initial superheat value being given to the system. The fuzzy logic controller must receive three inputs; the superheat temperature, the derivative of the superheat and the integral of the superheat. Since the fuzzy logic control outputs the number of steps the valve needs to be changed, these steps need to be converted into a delta superheat temperature in order to make the simulation work. To do this conversion a gain block is used. The value the gain block uses is 4 degrees of superheat for every 10 valve steps (numbers based on testing). The unit delay is set to the number of seconds that will pass between each sample taken by the system, which in this case is 10 seconds. The unit delay also allows the derivative block to function. The cumulative sum box keeps track of the delta superheat temperatures by summing up the delta superheat temperatures for ever iteration of the system. The XY Graph and scope blocks are used to view the superheat and derivative of the superheat in the form of a time based plot. Running the model with an initial superheat of $18^{\circ} \mathrm{F}$ over a time span of 100 seconds with 10 second intervals produces the plots seen in Figures 4 and 5 . Figure 4 shows that the fuzzy EEV simulation can be used to control the superheat at the inlet of the compressor to the needed value of $10^{\circ} \mathrm{F}$.

\section{Electronic Control Hardware}

The design of the hardware for the electronic control was broken up into five parts: power conditioning, motor drive, user output, system input and data analysis.

\section{Power conditioning}

- The purpose of this portion of the circuit is to convert the input $\mathrm{AC}$ voltage to $\mathrm{DC}$ voltage that can be used by the integrated circuits and the stepper motor. The power conditioning circuit is required to supply up to1A at $12 \mathrm{VDC}$ and25mA@3.3VDC.

\section{System input}

- System input refers to the different sensors in the system and control signals from the control board. This circuit needs to be able to interface the sensors to the control board and provide the control with input data from the system.

\section{Motor drive}

- The motor drive portion of the control is required to be able to commutate the stepper motor by means of signals from the microcontroller. In order to commutate the motor one complete step, a series of pulses to different phases of the motor windings is required. The microcontroller will be used to synchronize these pulses to the motor.

\section{User output}

- An LCD screen will be attached to the control board and will display valve position to the user. This will be used as a debugging tool and will not remain on the control board for 
production; therefore the LCD itself will not be factored into the cost constraint.

\section{Data analysis and control}

- This portion of the control is the computational part of the circuit and controls and monitors the entirety of the circuit. This section is voltage sensitive and requires tight tolerance.

\section{Description of the Design}

The sensor layout utilizes one pressure sensor and one temperature sensor at one state (the inlet of the compressor) in the compression vapor cycle of the geothermal heat pump (refer to Fig. 1). This sensor layout allows for a very accurate superheat calculation at this state in both heating and cooling modes. The superheat can be calculated by using the saturated temperature that corresponds to the pressure at this state and subtracting it from the actual temperature. As the superheat temperature changes going into the compressor, the control system will be able to adjust the expansion valve so that the superheat stays within the $10^{\circ} \mathrm{F} \pm 2^{\circ} \mathrm{F}$ range. Because there are no sensors located on either side of the expansion valve the control system will only be able to react to the superheat change at the inlet of the compressor. Also great care will need to be taken to make sure that the control system does not under or over compensate for the changes in the superheat by opening the valve too slowly or too quickly.

The electronic control for the EEV is based around a microcontroller for data processing of the fuzzy control algorithm. The microcontroller interfaces with the sensors, the stepper motor and the LED display. The microcontroller analyzes the state points in the system by sampling the output of the sensors and then adjusts the stepper motor accordingly. The display is controlled by the microcontroller as well, displaying the valve position. The microcontroller uses board space and does not require hardware interfacing with external memory.

The EEV changes the orifice opening by changing the position of the pin inside of the valve. The pin is attached to a permanent magnet rotor that is rotated by applying a specific series of voltages to the coils of the stator ring on the exterior of the valve. The valve and stepper motor were supplied by WaterFurnace. The motor is rated at 12 Volts DC and 0.26 Amperes per phase. In order to commutate the motor a driving circuit must be used because the voltage and current requirements of the stepper motor exceed what the microcontroller can deliver. A Darlington driver was selected to interface the stepper motor with the microcontroller. The four inputs to the Darlington driver are delivered from the microcontroller and the corresponding outputs of the Darlington driver are connected to the stepper motor.

The other facet of the electrical/electronic design is the software. The software is downloaded into the microcontroller and controls the functionality of the entire control. The software was written in the $\mathrm{C}$ programming language and compiled and developed in Atmel's software development environment, AVR Studio. AVR Studio connects to the Atmel STK500 development board through an RS232 serial cable. AVR Studio checks the code for errors, compiles the code and then communicates with the microcontroller to download the machine code to it.

The development board has features that make future design changes easier to implement. Some of these features include:
- A socket design for a removable microcontroller

- An increase in analog-to-digital ports for future sensor design layouts

- Readable display that outputs pressure, temperature, superheat and other calculations it is programmed to display.

The addition of more analog-to-digital ports allows more methods of control in the future, or to be used to improve the overall performance of the system. The socket for the microcontroller is useful because it allows the microcontroller to be removed from the development board, be programmed on the Atmel programming board and then placed back on the development board quickly. The display offers the user the benefit of displaying three-digit integer values, such as temperature and pressure that can be used for debugging purposes. This allows one to see if there are any issues with calculations or sensors.

\section{Parameters Testing and Procedure}

In order to obtain accurate and valid test results, the heat pump system needs to be setup by WaterFurnace to their specified test parameters. The room must be allowed to stabilize for a minimum of 15 minutes prior to testing to obtain initial readings of the system.

Before the testing begins 24VAC must be applied to the input of the switching power supply and the development board should then be turned on. The first test is to download the code to the microcontroller through the programming interface software, AVR Studio, to make sure that the microcontroller is functioning properly.

Once the functionality of the microcontroller is verified, the other components of the controller can be tested. At the startup of the controller, all of the LEDs and the three-digit display are tested to verify proper connectivity in the circuit. The second procedure that the controller executes is the calibration of the stepper motor. The controller commands the stepper motor to move past its maximum opening position, 480 , to verify that the valve is completely open before commanding the motor to close to its mid point, 240. An oscilloscope voltage probe is attached to the input of each motor inputs and the voltage waveform is monitored to verify that the motor is commutating. To ensure that the calibration routine behaves as expected, a data acquisition system in the testing lab must display a change in pressure and temperature in the system during the calibration procedure. Proper functionality of the calibration procedure also requires that the three-digit display shows the correct valve position at completion of the procedure

After calibration the control enters manual mode. In manual mode the controller only responds to user input from four pushbuttons: valve up, valve down, mode switch, and display switch pushbuttons. To verify that the valve up and valve down pushbuttons function correctly, each button is individually pressed and held for five seconds. The voltage waveform at the motor inputs is observed on the oscilloscope.

To test the sensor readings and their respective conversion algorithms, the three-digit display is used in conjunction with the display select pushbutton and the temperature, pressure and position LEDs. The display button is pressed so that the temperature LED is lit and a value is displayed on the threedigit display. The value is then compared to the reading on the 
data acquisition system in the lab. The display button is pressed again so that the pressure LED is lit and a value is displayed on the three-digit display. This value is compared to the pressure reading on the data acquisition system as well. The display pushbutton is pressed once more to show the valve position.

After completing the manual mode testing, the next step is to test the auto mode functionality. To set the system into auto mode the mode select pushbutton is held down for three seconds. The auto mode LED should be lit and the control algorithm is initiated. In auto mode, the control reads the temperature and pressure, calculates the saturated temperature from the pressure, and calculates the current superheat value and the change in superheat from the previous reading. After performing the appropriate measurements and calculations, the control enters the data into the fuzzy control algorithm to determine the appropriate number of steps and the value of the proportional gain. The control then commutates the motor the calculated number of steps. After commutating the control displays the temperature, pressure, saturation temperature, superheat, change in superheat, the number of steps that the valve commutated, and the valve position. This display sequence is used to verify the fuzzy algorithm's functionality by comparing the displayed values to the values of temperature, pressure, and superheat of the system from the data acquisition system in the lab. Auto mode will loop indefinitely keeping the system to a user specified superheat set point, even with the addition of a disturbance to the system.

Disturbance testing can be observed during testing by monitoring the data acquisition system's readings for temperature, pressure and superheat. Once the system reaches steady-state, a disturbance can be introduced into the system. The most rapid and severe disturbance to the system is a rapid change in the water temperature flowing through the coax heat exchanger. For example, in cooling mode the inlet water temperature can be increased from $77^{\circ} \mathrm{F}$ to $90^{\circ} \mathrm{F}$ to simulate a very hot day. Once the disturbance is introduced, the control display and laboratory data acquisition system will display the control's reaction.

\section{Component Testing Results}

All of the major components were individually tested and proven to work as designed. This includes the LEDs, pushbuttons, microcontroller, and sensors. The components worked together properly, and the logic of the control board interfaces with each component correctly. The fuzzy control algorithm was verified with hand calculations. This allows proper control of superheat using all of the components.

The user input and display interface operated according to the design specifications allowing the user to select the display mode, move the valve position up or down in manual mode and switch between manual and automatic mode. The pushbuttons provided an easy way for the user to control the position of the valve and gather the temperature, pressure, and position data. A recommendation to provide the user with more control of the board in manual mode is to implement a method of allowing the user to calibrate the valve when desired instead of manually having to reset the board.

\section{System Testing Results and Discussion}

The control was tested with a 3-ton geothermal heat pump system to ensure all of the design requirements were being met. This was done by interfacing the temperature and pressure sensors at the inlet of the compressor. Using the control board in auto mode, the EEV will commutate as an attempt to regulate superheat. The readings of temperature, pressure and superheat are displayed on the 7 segment LEDs on the board. These readings are then compared to values on Water Furnace's lab equipment. The superheat values, as well as the time it takes to reach $10^{\circ} \mathrm{F} \pm 2^{\circ} \mathrm{F}$ are recorded and evaluated. Four different system texts were carried out. All of these system tests were done at Water Furnace's development lab using a variety of equipment. The temperature and pressure ware monitored at the inlet and outlet of cycle components and displayed using data acquisition software. The development laboratory allows an implementation of real world conditions to be simulated such as air temperature, humidity, static pressure, and water flow rate and temperature at the inlet and outlet of the coax heat exchanger.

\section{Test \#1: Normal Operation Conditions}

The system was tested in the cooling mode (water is used in the coax to exchange heat from the refrigerant to the earth loop of a geothermal system) under normal operation conditions listed in Table 1. The lab was set to these conditions until steadystate was reached. At these listed conditions the superheat temperature was approximately $26^{\circ} \mathrm{F}$ at the inlet of the compressor. As shown in Fig. 6, the valve was capable of reducing the superheat to the set point of $10^{\circ} \mathrm{F} \pm 2^{\circ} \mathrm{F}$ at these conditions. It took about 5 minutes to reduce the initial superheat of $26^{\circ} \mathrm{F}$ to the set point of $10^{\circ} \mathrm{F} \pm 2^{\circ} \mathrm{F}$.

Table 1 Normal operation conditions

\begin{tabular}{|l|c|}
\hline \multicolumn{1}{|c|}{ Parameter } & ${ }^{\circ} \mathrm{F}$ \\
\hline Entering dry bulb air temperature & 80 \\
\hline Entering wet bulb air temperature & 66 \\
\hline Leaving dry bulb air temperature & 66 \\
\hline Leaving wet bulb air temperature & 40 \\
\hline Entering water temperature & 77 \\
\hline Leaving water temperature & 90 \\
\hline
\end{tabular}

\section{Test \#2: Operation with a change in coax inlet water temperature - Disturbance 1}

In the normal operation conditions stated Table 1 above, the inlet temperature of the coax water is $77^{\circ} \mathrm{F}$. In order to confirm that the control can handle a disturbance, such as an increase in the inlet water temperature was created. First the system was allowed to reach steady-state at normal operation conditions as described in Table 1. Next the inlet water temperature was increased from $77^{\circ} \mathrm{F}$ to $90^{\circ} \mathrm{F}$. This rapid increase in temperature is the worst-case disturbance that can only be realized in the lab. 
Figure 7 shows that as the water temperature changes, the level of the superheat changes. When this occurred, the fuzzy control algorithm begins to adjust the valve in order to bring the level of superheat to the desired point. The rate of change in the inlet water temperature was too great for the control to hold the superheat within the range initially. Once the water temperature stabilized at $90^{\circ} \mathrm{F}$ the fuzzy control algorithm was able to bring the superheat back down to the desired point. It should be noted that the inlet water temperature is typically $50^{\circ} \mathrm{F}$ to $77^{\circ} \mathrm{F}$, and this test was an exaggerated disturbance. This proves the control's functionality and capability during disturbances.

\section{Test \#3: Operation with a mode switch - Disturbance 2}

In order to further prove the control's ability to handle disturbance, another disturbance such as mode switching was introduced again from normal operation. The unit was again allowed to run in normal operation as described in Table 1 until steady-state was reached. The unit was then changed from cooling mode to heating mode. Figures $1 \mathrm{a}$ and $1 \mathrm{~b}$ show how the refrigerant switches directions when the mode (cooling and heating) is switched. When this happens the compressor turns off, then the reversing valve is switched to a different position. The compressor is then turned back on. This mode switching is done automatically with the unit's main controller. While the compressor is off, the EEV begins to recalibrate. When recalibrated, the EEV returns to the mid-way open point of 240 steps. The control is then put back into automatic mode to control the superheat temperature. Figure 8 shows the superheat with respect to time during the mode switching process. As can be seen from the figure, the fuzzy control algorithm begins to adjust the valve in order to bring the level of superheat to the desired point when a switching in mode occurs.

\section{Test \#4: Change in superheat set point}

Test \#4 is used to illustrate the fuzzy algorithm's ability to handle different set points of superheat. It could be possible for WaterFurnace to want a different set point of superheat at the inlet of the compressor in the future to accommodate design requirements. The set points of $5^{\circ} \mathrm{F}, 10^{\circ} \mathrm{F}$ and $15^{\circ} \mathrm{F}$ of superheat were programmed (note that only one set point can be programmed at a time) into the fuzzy logic portion of the code while the system was operating under normal conditions described in Table 1. After each set point was loaded, the superheat was measured until that set point was met. Figure 9 shows the control's ability to have a variety of set points programmed into it and function properly. The $5^{\circ} \mathrm{F}$ set point was not able to be reached because the valve was all the way open. It did however get in the $5^{\circ} \mathrm{F} \pm 2^{\circ} \mathrm{F}$ range.

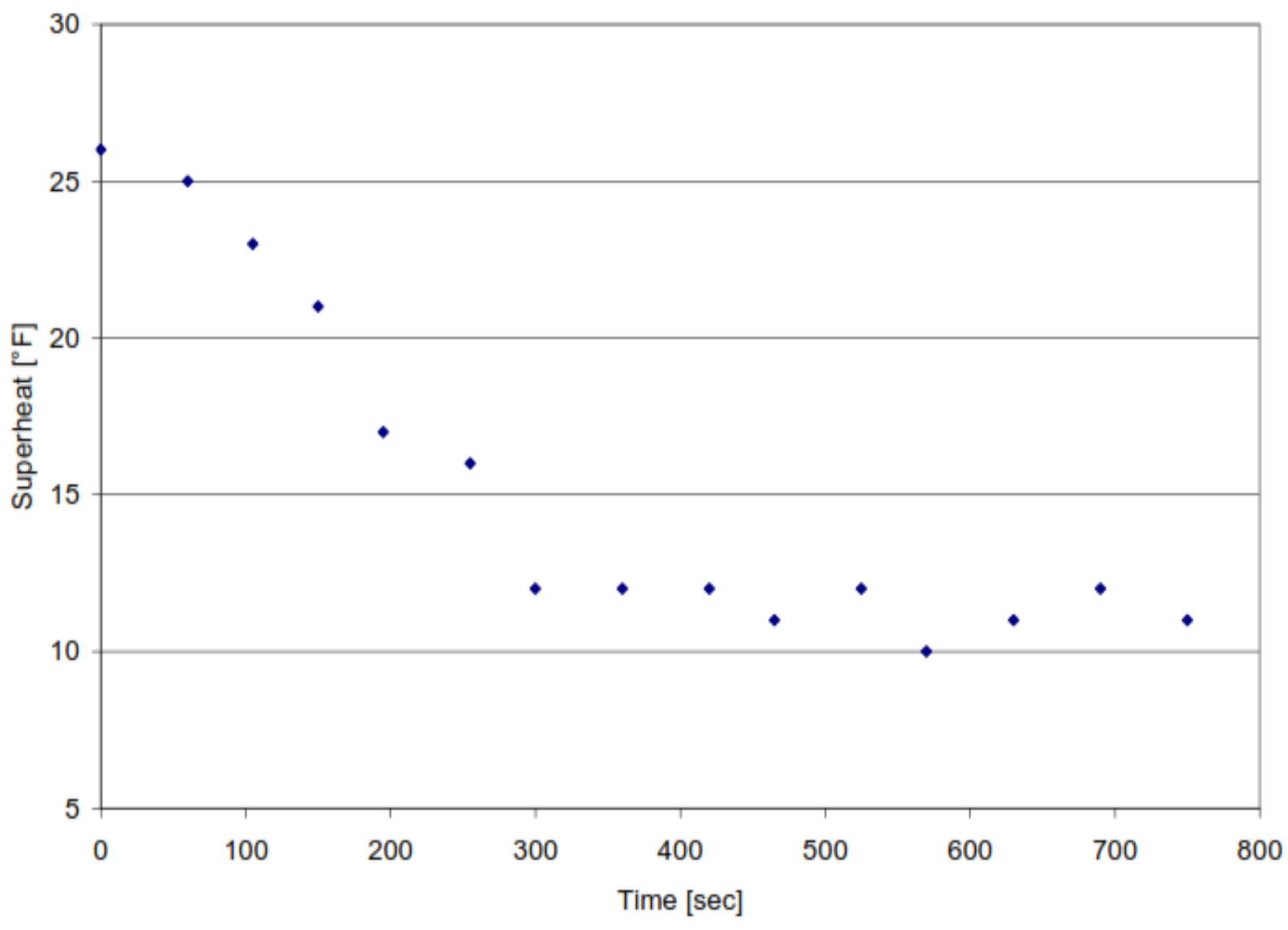

Fig. 6: Superheat control under normal operation conditions (Test \#1) 
Abu-Mulaweh et. al/ Int. J. of Thermal \& Environmental Engineering, 7 (2014) 1-10

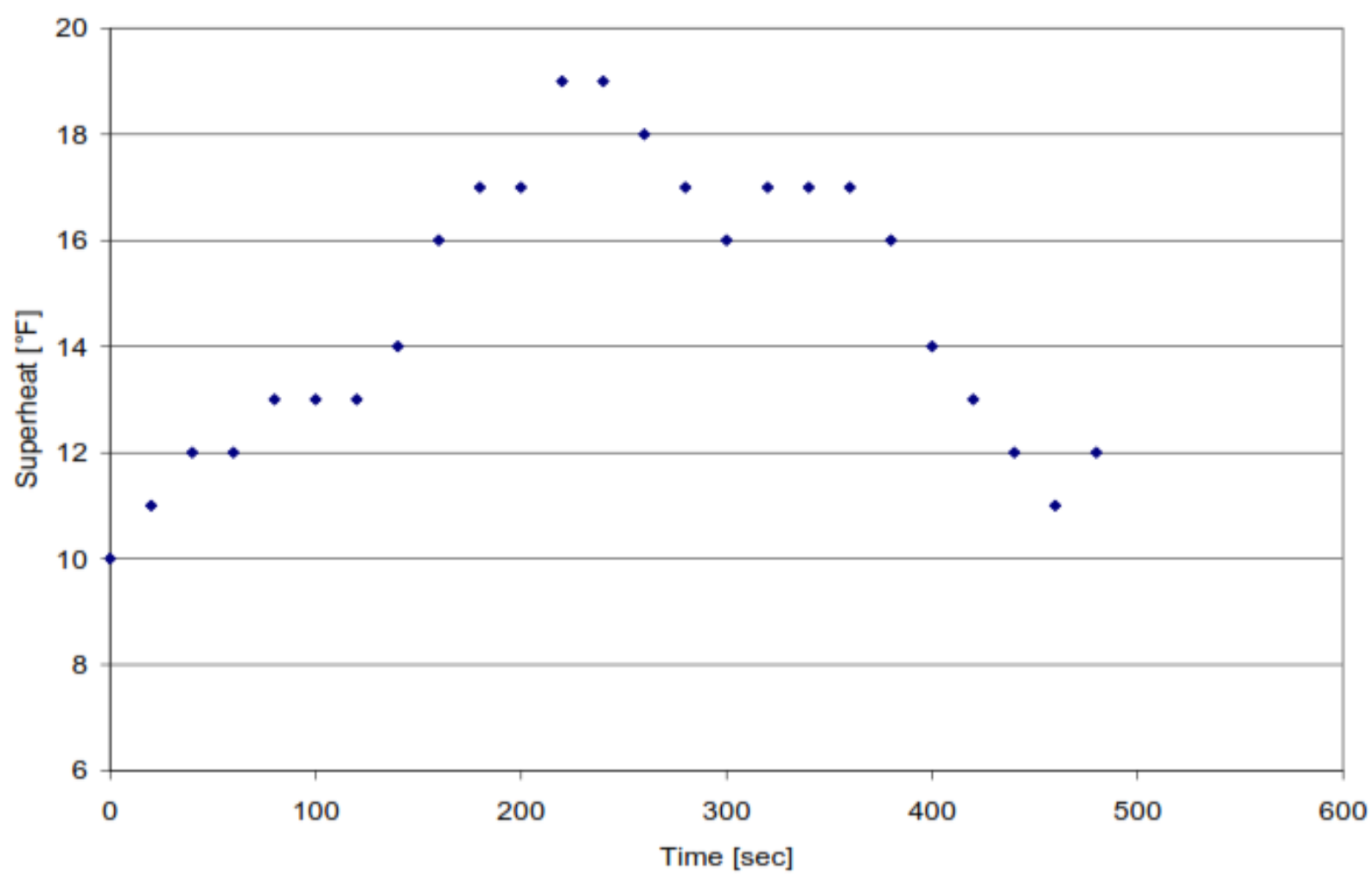

Fig. 7: Superheat control with a change in coax inlet water temperature (Test \#2)

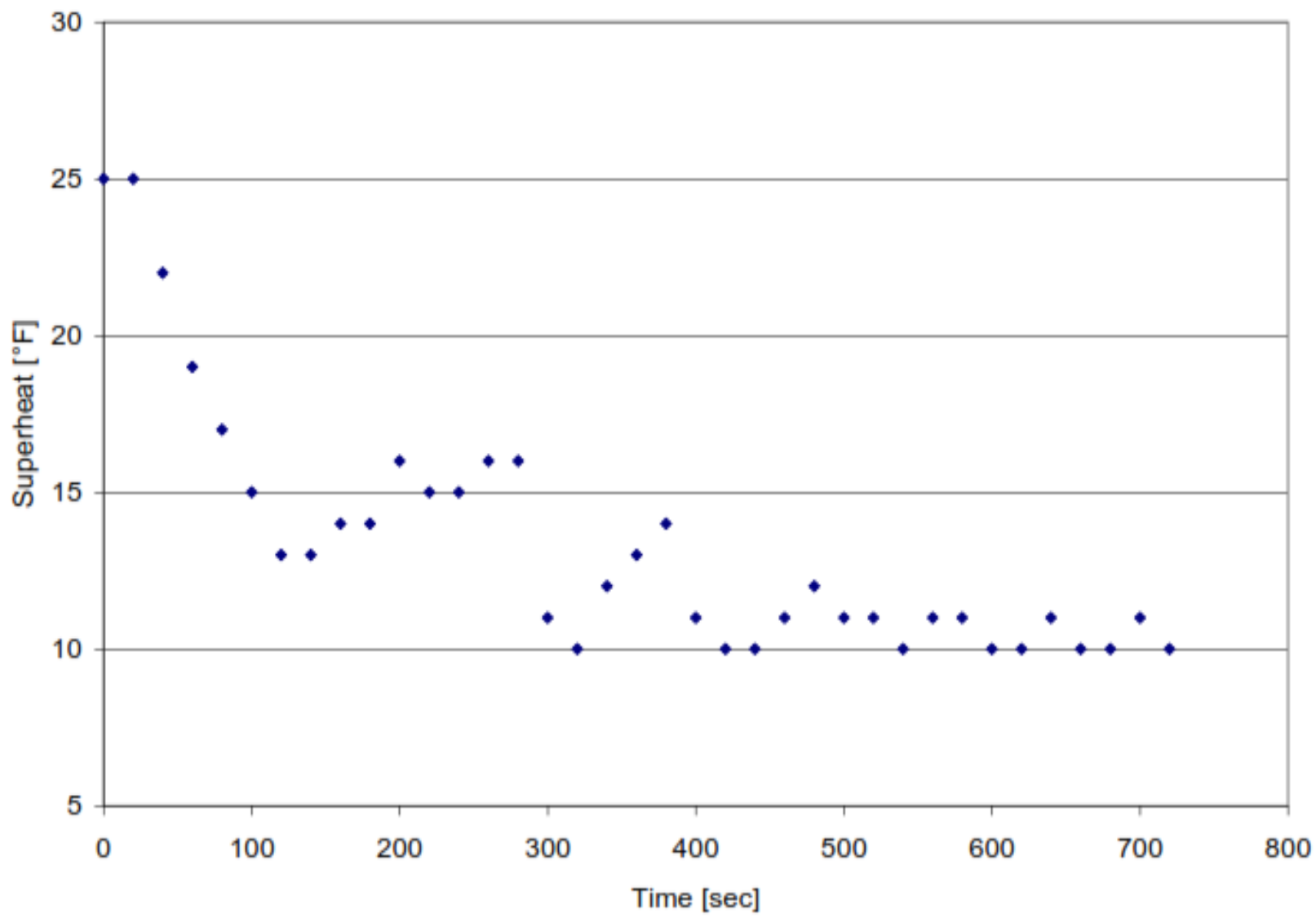

Fig. 8: Superheat control with a mode switch (Test \#3) 


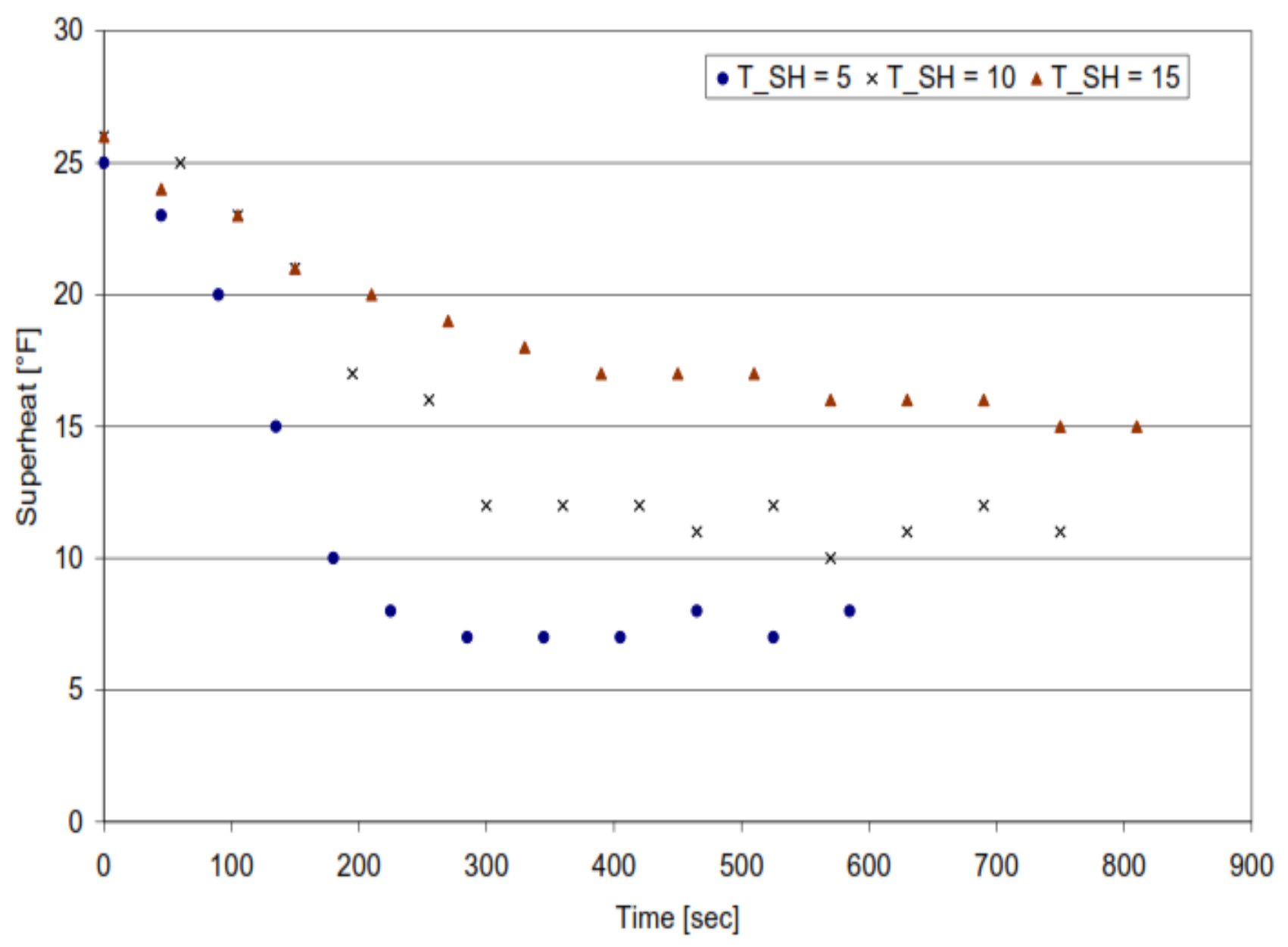

Fig. 9: Superheat control for different superheat values (Test \#4)

\section{Conclusion}

A development control board for an electronic expansion valve used in geothermal heat pump systems was designed and developed for the growing industry of energy conservation. The specific requirements of the board were given to the group by WaterFurnace, a geothermal heating and cooling system manufacturer. The design utilized a microcontroller based system with a fuzzy control algorithm, and a temperature and pressure sensor configuration at the inlet of the compressor. Then a bread board prototype was constructed and tested.

The controller was able to bring the superheat to the desired set point of $10^{\circ} \mathrm{F} \pm 2^{\circ} \mathrm{F}$ and maintain it there. A recommendation to further improve the performance of the controller is to implement another variable gain in the fuzzy control algorithm to improve the controller when the superheat is at or near the desired set point. This would lower the settling time of the controller when it is near the set point.

\section{Acknowledgement}

The present study was supported by Water Furnace International, Inc., Fort Wayne, Indiana, USA.

\section{References}

[1] P.M.T. Broersen and M.F. Van Der Jagt, Hunting of Evaporators Controlled by a Thermostatic Expansion Valve, ASME Transactions 1 (1980), pp. 130-135.

[2] P. Mithraratnel, and N.E. Wijeysundera, , An Experimental and Numerical Study of Hunting in Thermostatic-Expansion-Valve-Controlled Evaporator, International Journal of Refrigeration $\mathbf{2 5}$ (2002), pp. 992-998.

[3] W. Chen, Z. Chen, R. Zho, and Y. Wu, Experimental Investigation of a Minimum Stable Superheat Control System of an Evaporator, International Journal of Refrigeration 25 (2002), pp. 1137-1142.

[4] A. Outtagart, P. Haberschill, and M. Lallemand, The Transient Response of an Evaporator fed through an Electronic Expansion Valve, International Journal of Energy Research 21 (1997), pp. 793-807.

[5] C. Aprea, and R. Mastrullo, Experimental Evaluation of Electronic and Thermostatic Expansion Valves Performances Using R22 and R407C, Applied Thermal Engineering 22 (2002), pp. 205-218. 
[6] R. Lazzarin, D.Nardotto, and M. Noro, Energy Savings and Economic Benefits of Using Electronic Expansion Valves in Supermarket Display Cabinets, International Journal of Low-Carbon Technologies 3 (2008), 147-157.

[7] R. Lazzarin and M. Noro, Experimental Comparison of Electronic and Thermostatic Expansion Valves Performances in an Air Conditioning Plant,
International Journal of Refrigeration, 31 (2008), pp. 113-118.

[8] A. Bejan, G. Tsatsaronis, and M. Moran, Thermal Design \& Optimization," John Wiley \& Sons, Inc. New York, USA, (1996).

[9] Y. Jaluria, Design and Optimization of Thermal Systems," McGraw-Hill, New York, USA, (1980). 